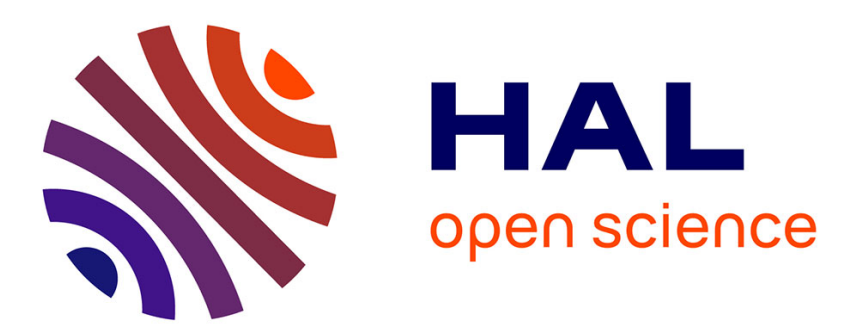

\title{
Characterization of forming limits at fracture with an optimized cruciform specimen: Application to DP600 steel sheets
}

Xiao Song, Lionel Leotoing, Dominique Guines, Eric Ragneau

\section{To cite this version:}

Xiao Song, Lionel Leotoing, Dominique Guines, Eric Ragneau. Characterization of forming limits at fracture with an optimized cruciform specimen: Application to DP600 steel sheets. International Journal of Mechanical Sciences, 2017, 126, pp.35-43. 10.1016/j.ijmecsci.2017.03.023 . hal-01493246

\author{
HAL Id: hal-01493246 \\ https://hal.science/hal-01493246
}

Submitted on 21 Mar 2017

HAL is a multi-disciplinary open access archive for the deposit and dissemination of scientific research documents, whether they are published or not. The documents may come from teaching and research institutions in France or abroad, or from public or private research centers.
L'archive ouverte pluridisciplinaire HAL, est destinée au dépôt et à la diffusion de documents scientifiques de niveau recherche, publiés ou non, émanant des établissements d'enseignement et de recherche français ou étrangers, des laboratoires publics ou privés. 


\title{
Characterization of forming limits at fracture with an optimized cruciform specimen: application to DP600 steel sheets
}

\author{
X. Song, L. Leotoing*, D. Guines, E. Ragneau \\ Institut National des Sciences Appliquées de Rennes (INSA) - LGCGM EA 3913, $20 \mathrm{Av}$. \\ des Buttes de Coësmes, CS 70839, 35708 Rennes Cedex 7, France
}

\begin{abstract}
In order to identify experimental limit strains at fracture for metallic sheets under in-plane biaxial loadings, a specific specimen shape has to be defined. Ideally, the proposed geometry must lead to fracture at the specimen center whatever the strain path imposed by the experimental device. If such condition is ensured, the whole strain paths ranging from equi-biaxial to uniaxial could experimentally investigated. Based on literature review, four in-plane cross specimen shapes have been selected owing to strong potential to reach large strain and fracture in their central point. From finite element simulations, the behavior of these different shapes is evaluated. Based on these numerical results, a new shape is proposed and optimized for determining the forming limits at fracture of DP600 sheet metal with a thickness of $2 \mathrm{~mm}$. The forming limit strains at fracture are identified by a timedependent method and the forming limit strains at necking are determined by a position-dependent method. The experimental forming limit strains at fracture of DP600 sheet metal are fitted by a forming line. Three ductile fracture criteria are then calibrated with experimental points. The Oyane criterion with two parameters gives the best prediction.
\end{abstract}

Keywords: optimized cruciform specimen, experimental forming limits at fracture, prediction of ductile fracture

\footnotetext{
*Corresponding author

Email addresses: xiao.song@insa-rennes.fr (X. Song), lionel.leotoing@insa-rennes.fr (L. Leotoing), dominique.guines@insa-rennes.fr (D. Guines), eric.ragneau@insa-rennes.fr (E. Ragneau)
} 


\section{Introduction}

In the automotive industry, advanced high-strength steels (AHSS) are adopted for vehicule safty and fuel economy. DP600 is a type of AHSS steels with high strength, ductility and formability $[1,2]$. The increasing application of DP steels demands in-depth analysis of their forming behaviour for optimal use [3]. In the forming process of sheet metals, forming limits are generally defined by localized necking but not ductile fracture. Recently, some researchers $[4,5]$ have proposed that ductile fracture can appear without the occurrence of localized necking in traditional sheet metal forming process or single point incremental forming process. The forming limit curve at necking (FLCN) should be replaced by the forming limit curve at fracture (FLCF) to describe failure of sheet metals $[6,7]$.

In previous studies $[8,9]$, different traditional tests (for example, single tensile test, bulge test, Nakazima test and hemispherical dome test) are used to construct FLCF. These tests require various specimen geometries if a wide range of strain path has to be characterized. Depending on the test, results can be affected by friction between tools and sample, and by sample bending. In the last few years, the in-plane biaxial tensile test with a dedicated cruciform specimen has been proposed to identify forming limits at necking under linear paths [10] and non-linear paths [11]. Recently, with the same specimen shape, this test has also been used to determine the forming limits at fracture [7]. As explained in this previous work, the test is interesting to overcome the drawbacks of the conventional sheet formability tests for determination of forming limits at fracture : no influence of bending, no friction and linear or non-linear strain paths with or without pre-strain can be applied to the material. Nevertheless, investigations of necking or fracture limits with the in-plane biaxial tensile test require the use of a complex specimen shape. Indeed, the specimen geometry, usually a cross specimen, must exhibits a fracture at the central point of the specimen to control the strain path thanks to the displacement imposed on the two perpendicular axes. In [7], an initial sheet thickness of $4 \mathrm{~mm}$ is necessary to manufacture the cross specimens since a notable thickness reduction is required in the specimen central area to force fracture at the center point. Although specimens of cruciform type have been investigated quite intensively, no standards exist 
when large deformations are required in the central zone [12]. In order to control the strain path and to reach fracture whatever the imposed strain path, the specimen shape design must ensure both the maximum strain occurs at the center point and reduce stress concentrations in peripheral regions. Classically, three sensitive areas can be identified in the cruciform specimen geometry: (i) the arms, (ii) the transition zone between two arms, and (iii) the central zone [13].

For the design of arms, Prates et al. [14] used a tapered arm to lead the strains to the central area of specimen for determining the constitutive parameters. Tapered arms were also used by Abu-Farha et al. [15] for biaxial tests at elevated temperatures (up to $300{ }^{\circ} \mathrm{C}$ ) and under quasi-static conditions until facture. It was found that an increase of the tapered angle, in conjunction with a smoothly varying thickness profile, shifts plastic deformation closer to the central gauge area. Kuwabara et al. [16] adopted a cruciform specimen with slots in the arms to investigate the work hardening behavior of cold-rolled steel sheet. The seven slots in each arm were made with laser. The authors considered that slots in arms were very effective in making the strain distribution in the gauge section almost uniform. Kuwabara et al. [17] also used this cruciform specimen to study the steel sheet yield locus and work hardening characteristics. The same approach was adopted by Merklein et al. [18] with the definition of six slots in each arm. However, the introduction of the slots results in a reduction of the arm cross-section which becomes more compliant than the central section. As a result, arms deform excessively under load and limit the amount of useful strain in the central zone before failure. To overcome this problem, either the thickness of the central zone should be reduced or multiple layers of the arm should be stacked together so that the comparative rigidity of arms increase [19].

For the transition zone between arms, Müller et al. [20] and Banabic et al. [21] proposed notches to investigate the yield criterion. The results showed that a large zone of homogeneous deformation with relatively high strain ( $12 \%$ for the equivalent strain) before instability was obtained. Abbassi et al. [22] have used a cruciform specimen with a large radius of notch to perform an analysis of instability and fracture during complex loading by addressing the influence of ductile damage evolution in necking process. Two different cruciform specimens were compared by Makris et al. [23]: one specimen with constant arm width and the other one with a spline corner fillet. The 
equibiaxial loading was considered for the comparison of two shapes. The result of the numerical optimization showed that the second shape leads to higher damage concentration in the center of cruciform specimen.

Considering the design of the central zone, Makinde et al. [24, 25] have designed two different cruciform specimens: a circular central section with reduced thickness for tests with small strains and a squared central section with reduced thickness and slots in the arms to reach large strains. Tasan et al. [26] considered that it is not possible to achieve the fracture in the central region by only adjusting the in-plane geometry of the cruciform. Based on finite element simulations, they identified three parameters to be optimized (radius of central zone, final thickness, thickness profile of thinner zone) for a strain localization in the center of the cruciform specimen. When a flat thickness-reduced zone is adopted, the localization initiates at the corner fillet of the thickness reduced zone, as observed in [27]. Lee et al. [28] proposed a cruciform specimen to construct the first quadrant of FLD. The central zone was reduced by two steps. The first reduction is a circle and the second reduction is a square with rounded corner and with edges rotated by $45^{\circ}$ relative to the axes of the arms. The results showed that the prediction of FLD with the modified Cockcroft criterion meets well with experiments. Zidane et al. [29] designed a cruciform specimen including a two-step thickness reduction in the central zone to investigate the whole FLCN of AA5086 sheets.

Based on literature, the following rules have to be considered to design a cruciform specimen shape for investigating fracture: (i) the tapered arm helps to shift plastic deformation closer to the central zone; (ii) the slots in arms are very effective in making the strain distribution in the central zone almost uniform. Narrow, multiple and equally-spaced slots are preferable for homogeneous strains; (iii) the increase of the notch depth promotes plastic deformation closer to the central zone; (iv) the thickness reduction of central zone is essential for the onset of fracture at the specimen central point.

In this study, three objectives are pursued. The first one is to design a dedicated cruciform specimen for investigating the forming limits at fracture of DP600 sheet metal with a thickness of $2 \mathrm{~mm}$. From previous work about in-plane biaxial tensile tests, some specimen shapes are selected. Their potential to reach large strains at the central point of the specimen is numerically investigated. Based on these numerical results, an optimization of a new specimen shape is performed. The second objective is to validate experi- 
mentally the suggested shape. Experimental in-plane biaxial tensile tests are done with the optimized cruciform specimen under a wide range of strain path. Following the methodology presented in [7], the experimental forming limit curve at fracture is plotted. The last objective focuses on the capability of three classical ductile fracture criteria to predict the onset of fracture for a DP600 steel. Through a FE model of the cruciform specimen, the three selected fracture criteria are first calibrated from experimental fracture limits of one or two strain paths. Then the numerical model is used to predict the whole FLCF for strain paths ranging from biaxial to uniaxial strain states.

\section{Cruciform specimen design}

\subsection{Re-design of cruciform specimens}

Four cruciform specimens reported in literature [26, 28, 29, 27] are selected due to their potential to develop large strains in the central zone. As shown in Figure 1, the original sheet thickness is fixed to $2 \mathrm{~mm}$ for all the shapes. The length $(160 \mathrm{~mm})$ is imposed by the space requirements of the test machine. The width of arms $(30 \mathrm{~mm})$ is re-dimensioned considering the technical specifications of the experimental device (maximum load capacity of $50 \mathrm{kN}$ on each axis). The minimal thickness of the central zone is set to $0.75 \mathrm{~mm}$. A smaller thickness would cause early fracture due to the small defects produced by the milling process. With this set of fixed dimensions, for each specimen shape, a parametric investigation has been considered to define the best set of values (dimensions of reduced zone, radii, notches, slots) to get large strains in the center and minimize strain localization in peripheral zones.

For specimen 1, the thickness of the circular zone varies along a circle arc profile in the thickness direction. The central zone of the specimen 2 is a two steps thickness-reduced geometry. The shape of the first thickness reduction is a square with rounded corners and with edges rotated by $45^{\circ}$ relative to the axes of the arms, while the shape of the second thickness reduction is a circle with flat bottom. Four tapered arms are also included. For specimen 3, the thickness reduction is devided into two steps. The first step of thickness reduction is a square with edges parallel to arms and the second step of thickness reduction is circular with an arc profile in the thickness direction. Four identical slots are added for each arm. For specimen 4, the thicknessreduced zone is a circle with a flat bottom. Four slots are arranged on each 
arm around the central zone with different locations for median and outer slots.

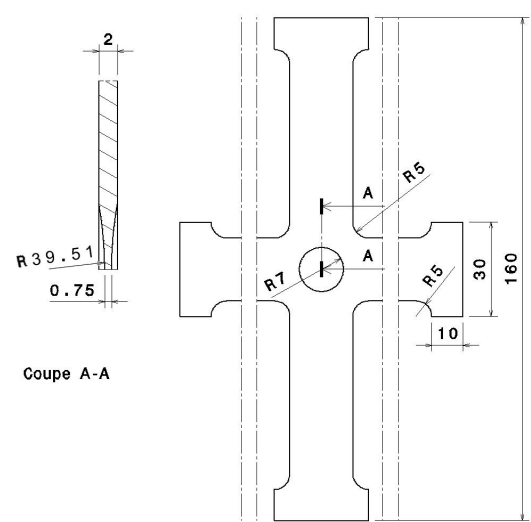

(a) Specimen 1

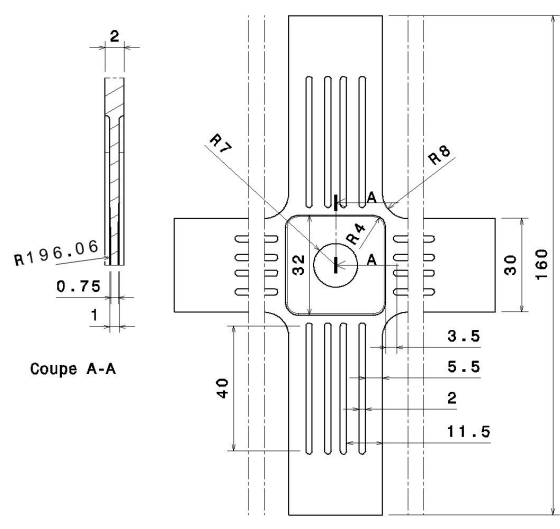

(c) Specimen 3

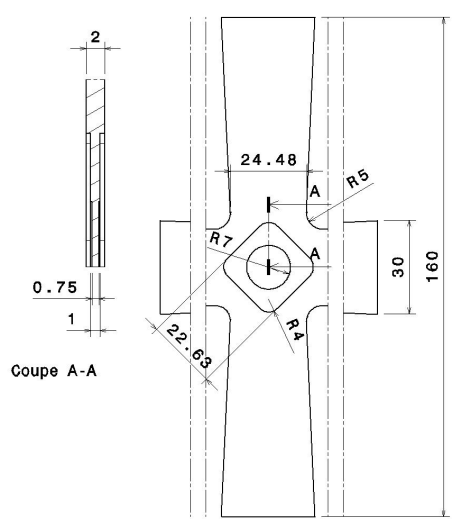

(b) Specimen 2

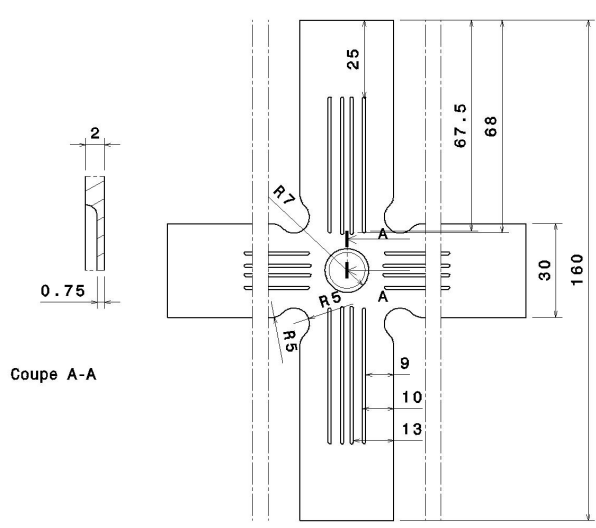

(d) Specimen 4

Figure 1: Geometries of re-designed cruciform specimens

\subsection{Numerical simulation}

Based on the selected geometries, four FE models have been defined with the ABAQUS code. Considering the symmetrical properties of specimens, only one-quarter is modeled. The linear tetrahedral solid elements are adopted for the mesh. A refined mesh is defined in the central area. Equibiaxial tensile tests under quasi-static conditions are simulated. The 
identification of DP600 steel behaviour, subjected to in-plane equibiaxial loadings, was performed in a previous work [30] for a strain rate ranging from quasi-static to intermediate strain rate. In [30], the hardening law of DP600 was identified for high strain levels which makes reliable the calculation of stress field in the range of limit strains. This point will be essential for the numerical evaluation of ductile fracture criteria. Based on this work, the material constants and models used in the present work are briefly recalled hereafter:

Young's modulus of $200 \mathrm{GPa}$ and Poisson's ratio of 0.3 are considered for the isotropic elasticity. For the plastic behaviour, the associated normal flow rule is assumed and Hill48 yield criterion for plane stress condition is adopted. As shown in Table 1, the parameters of Hill48 yield criterion for DP600 have been calculated from three anisotropic coefficients proposed by Ozturk et al [31].

Table 1: Lankford's coefficient and Hill48 yield parameters

\begin{tabular}{ccccccccc}
\hline$r_{0}$ & $r_{45}$ & $r_{90}$ & $\mathrm{~F}$ & $\mathrm{G}$ & $\mathrm{H}$ & $\mathrm{L}$ & $\mathrm{M}$ & $\mathrm{N}$ \\
\hline 0.89 & 0.85 & 1.12 & 0.420 & 0.529 & 0.471 & 1.500 & 1.500 & 1.282 \\
\hline
\end{tabular}

The general strain rate dependent hardening law on the basis of Ludwick's formulation [30] is used:

$$
\bar{\sigma}=\sigma_{0} \dot{\varepsilon}^{m_{1}}+K \varepsilon_{p}{ }^{n} \dot{\varepsilon}^{m_{2}}
$$

The parameters $\sigma_{0}, \mathrm{~K}, \mathrm{n}, m_{1}$ and $m_{2}$ are given in Table 2 .

Table 2: Identified parameters of the rate-dependent hardening law for Hill48 yield criterion $[30]$

\begin{tabular}{ccccc}
\hline$\sigma_{0}(\mathrm{MPa})$ & $\mathrm{K}(\mathrm{MPa})$ & $\mathrm{n}$ & $m_{1}$ & $m_{2}$ \\
\hline 339.2 & 839.7 & 0.3864 & 0.0052 & 0.0158 \\
\hline
\end{tabular}

All the numerical results are given at the moment corresponding to a maximum value of major principal strain of $20 \%$ on the inside of the specimen. At the same time, fields of both major principal strain and equivalent plastic strain and their evolution along a specified path (path 1 to 4) are analyzed for each specimen (Figure 2 to Figure 5). 
Figure 2 shows the numerical results for specimen 1 . The maximum value of major strain and the maximum value of equivalent plastic strain are located in the arms. From the evaluations of major strain and equivalent plastic strain along path 1, it can be seen that the major strain is higher in the arms $(20 \%)$ than in the central point $(7 \%)$. With such a shape, failure will occur in the arms where an uniaxial tension strain state develops.

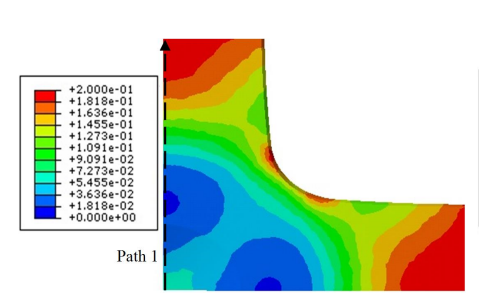

(a) Major strain

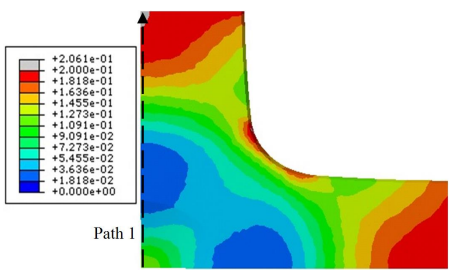

(b) Equivalent plastic strain

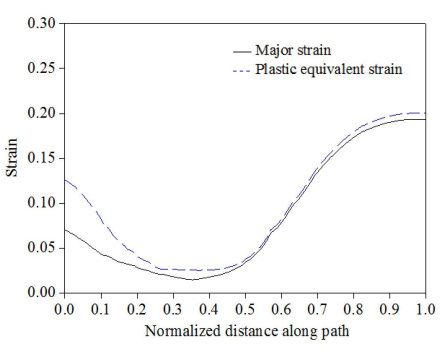

(c) Strain evolution

Figure 2: Numerical results of specimen 1

For specimen 2, as observed with strain fields (Figure 3 (a) and (b)) and with the strain evolution along the diagonal path 2 (Figure 3 (c)), a homogeneous strain field is reached in the central region. Unfortunately, the maximum value of major strain $(20 \%)$ and the maximum value of equivalent plastic strain (20\%) are localized at the transition zone of arms (under uniaxial tensile state). At the central point, the maximum value of major strain is $6 \%$. The equivalent plastic strain presents two rapid changes at the transition between two zones with different thicknesses. In this case, the failure will happen at the corner radius between two arms.

For specimen 3 (Figure 4), the maximum value of major strain is reached at the slot tip (under uniaxial stretching). At the same time, an equivalent plastic strain of $18 \%$ is reached at the central point under equibiaxial stretching. So for this shape, the fracture will probably initiate at the end of slot (see Figure 4 (c)) where the major strain is higher (20\%) than the one at the central point $(9 \%)$.

Figure 5 shows the numerical results for specimen 4 . Both, the maximum value of major strain and equivalent plastic strain are located at the tip of slots. As observed along the path 4, the major strain is much higher at the slot end (20\%) than at the central point (7\%). Another strain localization 


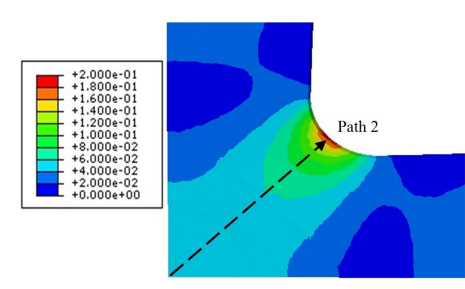

(a) Major strain

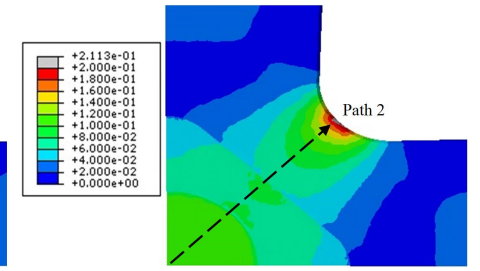

(b) Equivalent plastic strain

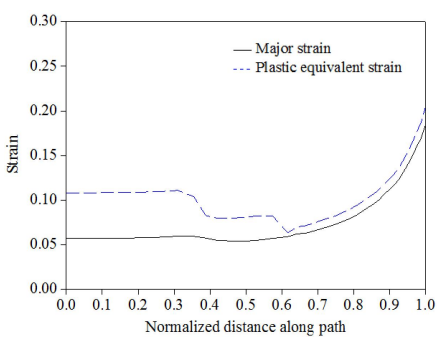

(c) Strain evolution

Figure 3: Numerical results of specimen 2

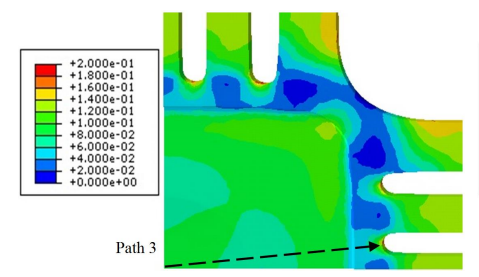

(a) Major strain

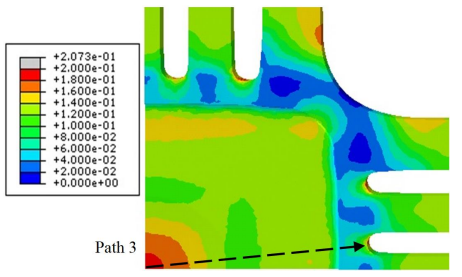

(b) Equivalent plastic strain

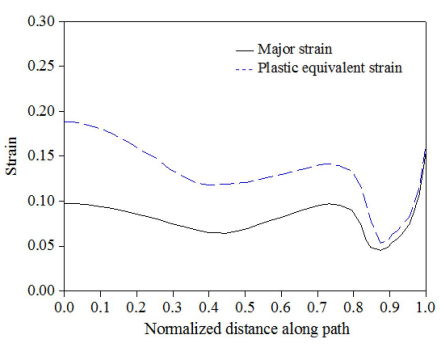

(c) Strain evolution

Figure 4: Numerical results of specimen 3 
appears in the fillet radius between the flat reduced thickness central zone and the rest of specimen.

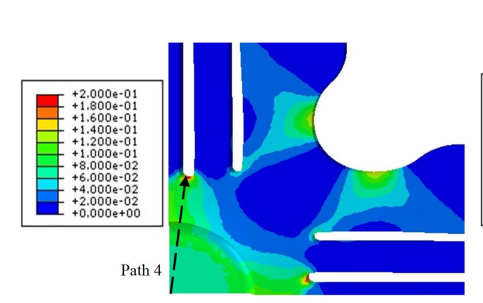

(a) Major strain

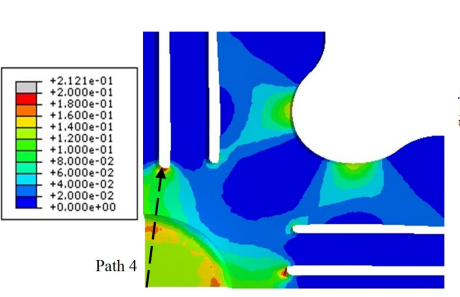

(b) Equivalent plastic strain

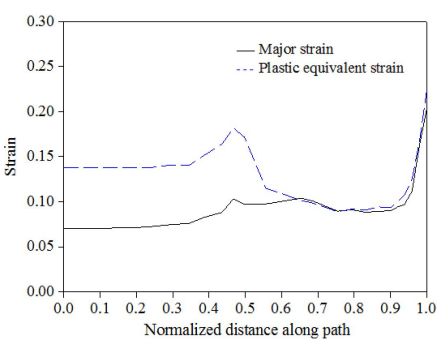

(c) Strain evolution

Figure 5: Numerical results of specimen 4

Clearly, Figure 4 and 5 show the interest of slots since higher values of maximal principal strain are measured at the central point of the specimen and strain difference between localization points of strains and the central point is minimized.

\subsection{Optimized cruciform specimen}

Based on the above results, a new cross shaped specimen is proposed, as shown in Figure 6. In the thickness direction of the circular reduced zone (radius of $7 \mathrm{~mm}$ ), a circle arc profile is adopted to generate strain localization at the central point. Six slots are defined for each arm and the arrangement of slots is optimized.

As shown in Figure 7, a FE model has been built with 3D tetrahedral elements and a refined mesh in the central area.

Figure 8 shows the numerical results of the optimized specimen. The maximum value of major strain reaches $20 \%$ at the slot tip and $18 \%$ at the central point of the specimen. At the same moment, a value of $35 \%$ of equivalent plastic strain is reached at the central point. It can be seen that the values of major strain and equivalent plastic strain are much higher at the central point than in arms or in transition zones of arms. Therefore, this optimized cruciform specimen shape presents an interesting potential and will be experimentally evaluated in order to plot the whole FLCF of $2 \mathrm{~mm}$ thickness steel sheets of DP600 grade.

For optimizing the shape of cruciform specimen, a gradual thickness reduction in the central zone is essential to observe strain localization and 


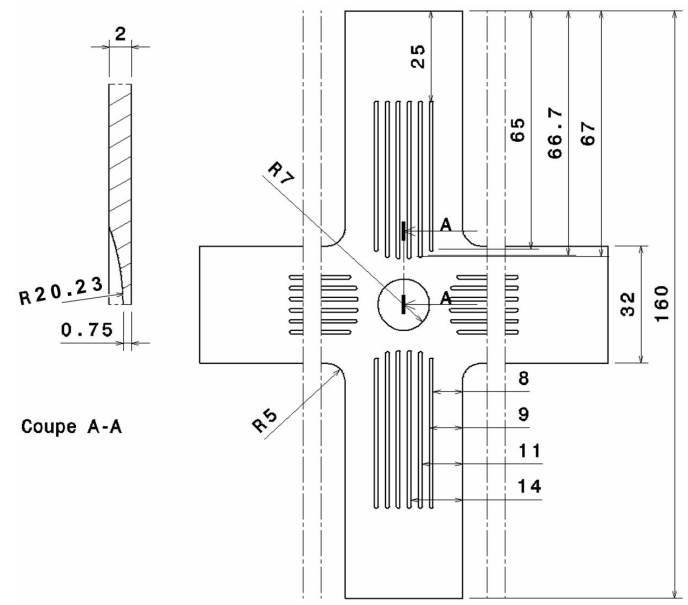

Figure 6: Geometry of optimized specimen

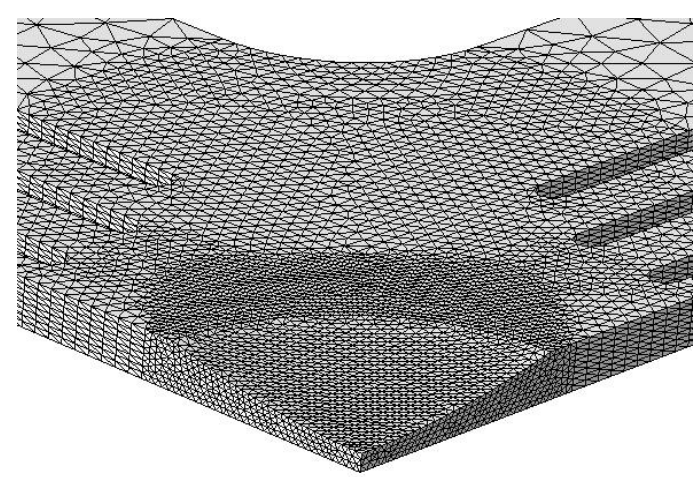

Figure 7: 3D Mesh of the cruciform specimen

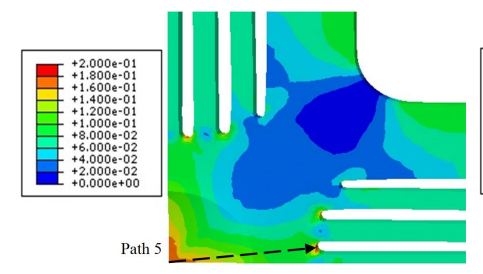

(a) Major strain

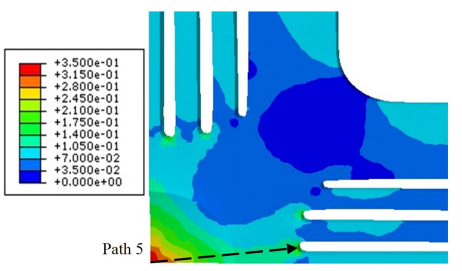

(b) Equivalent plastic strain

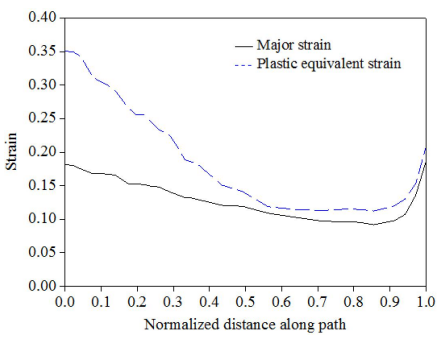

(c) Strain evolution

Figure 8: Numerical results of optimized specimen 
fracture in the center. Meanwhile, the addition of slots limits high strains in transition zones of arms. This effect is emphasized with a high number of slots. The position of the ends of slots has also to be considered and optimized.

\section{Experimental validation}

\subsection{Biaxial testing machine and strain measurement}

As shown in Figure 9, a servo-hydraulic testing machine equipped with four independent dynamic actuators is used. The central area of the cruciform specimen can be deformed under various strain paths when different speeds are used on the two perpendicular axes of the machine. Here, a speed of $1 \mathrm{~mm} / \mathrm{s}$ is used for the two axes to produce the equibiaxial tension state.

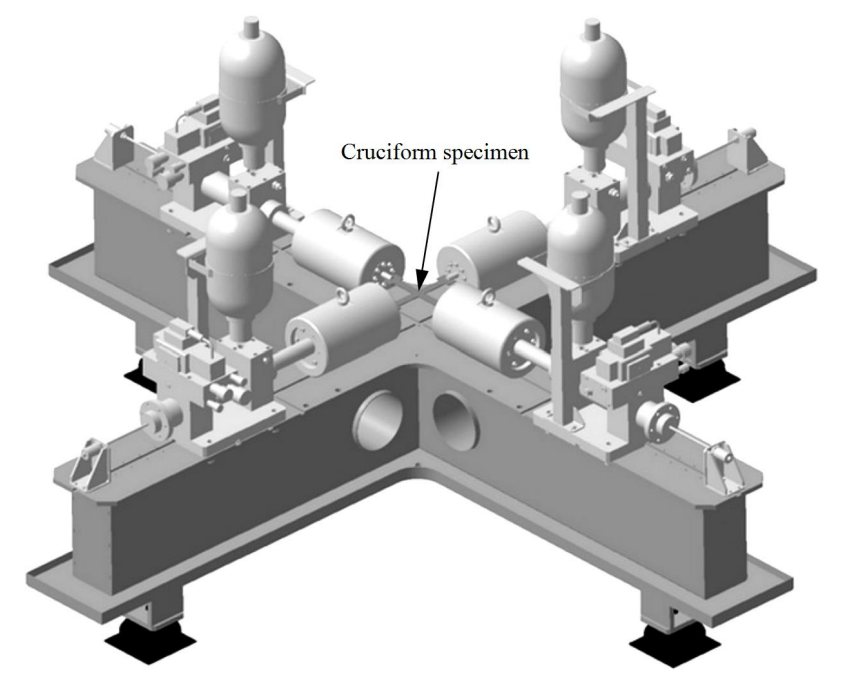

Figure 9: The in-plane biaxial tensile machine

The digital image correlation (DIC) is adopted to evaluate the surface strain components during the tests. A Fastcam APX-RS camera is adopted to take continuous images and an acquisition of 250 frames/s is used. A random speckle pattern is needed in the DIC method and the plane surface of the non-reduced side of central zone is used to produce the random speckle pattern. 


\subsection{Identification of fracture and necking}

Depending on the strain evolution and the surface images of specimen, a time-dependent method is adopted to determine the appearance of fracture and to obtain the forming limit strains at fracture [7]. The equivalent strain field for an area of $2.4 \times 2.4 \mathrm{~mm}$ in the center is presented in Figure 10 at time $0.004 \mathrm{~s}$ before fracture. The evolution of the equivalent strain at point A is plotted in Figure 11. As shown in this figure, the macroscopic crack (Figure $12(\mathrm{~b})$ ) occurs with an abrupt change of equivalent strain in a very short time $(0.004 \mathrm{~s})$. The major and minor strains of the central area at the moment just before the appearance of macroscopic fracture are used as the forming limit strains at fracture.

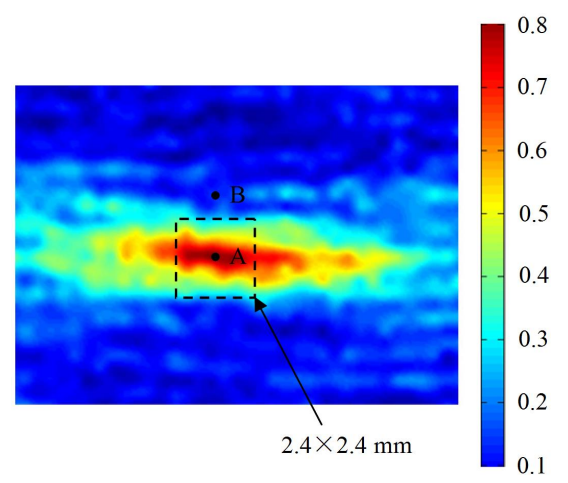

Figure 10: Equivalent strain field of the central area at the time 0.004s before fracture

A critical ratio method applied in previous works $[11,32]$ is used to identify forming limit strains at necking. As shown in Figure 13, when the necking occurs in the central zone (point A in Figure 10), the level the equivalent strain increases abruptly due to the appearance of the plastic instability. Outside the necking zone (point B in Figure 10), the level of equivalent strain stops increase. The equivalent strain increment ratio between point $\mathrm{A}$ and point $\mathrm{B}$ reaches a critical ratio (value of 4 in this study) for the onset of necking, and the corresponding major and minor strains of point A define the forming limit strains at necking.

\subsection{Experimental results}

As shown in Figure 14, experiments are produced under different strain paths from uniaxial to equibiaxial stretching. The solid markers and dashed 


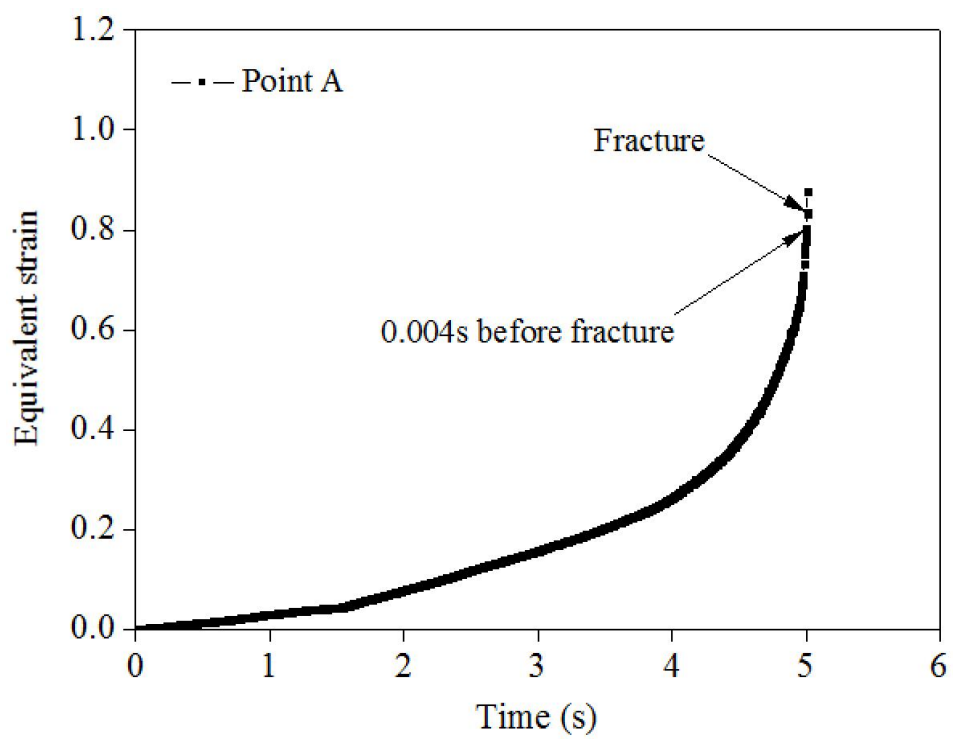

Figure 11: Identification of fracture

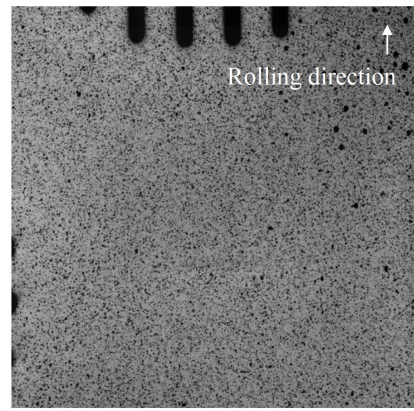

(a) $0.004 \mathrm{~s}$ before fracture

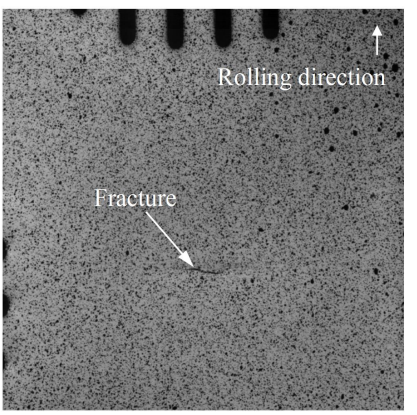

(b) fracture

Figure 12: DIC images of the specimen surfaces 


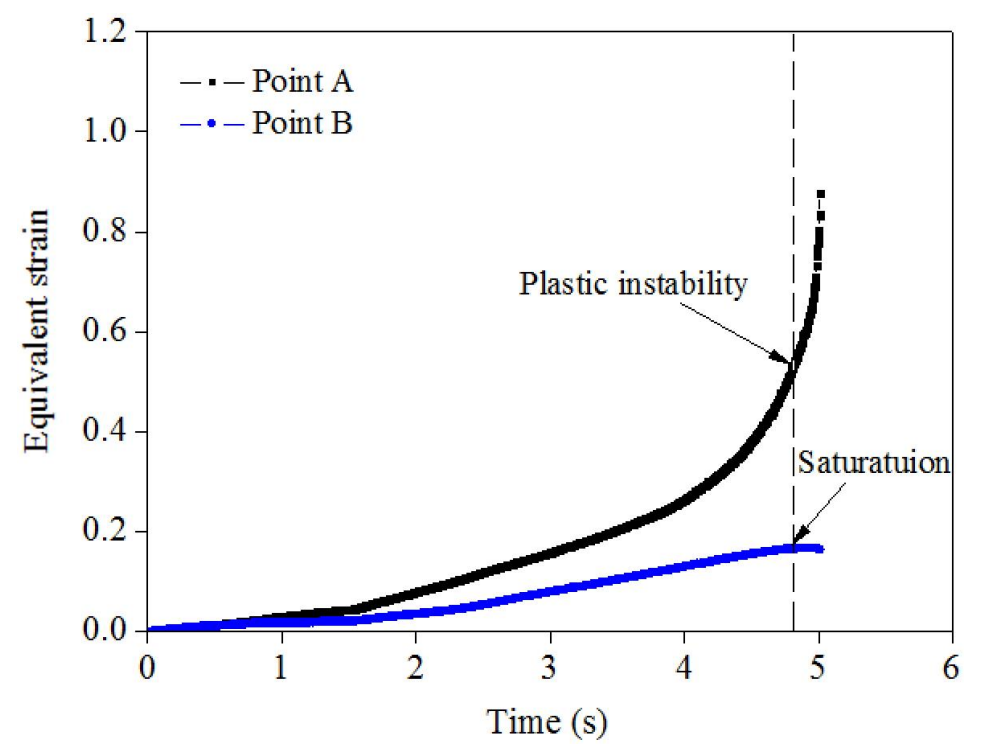

Figure 13: Identification of necking

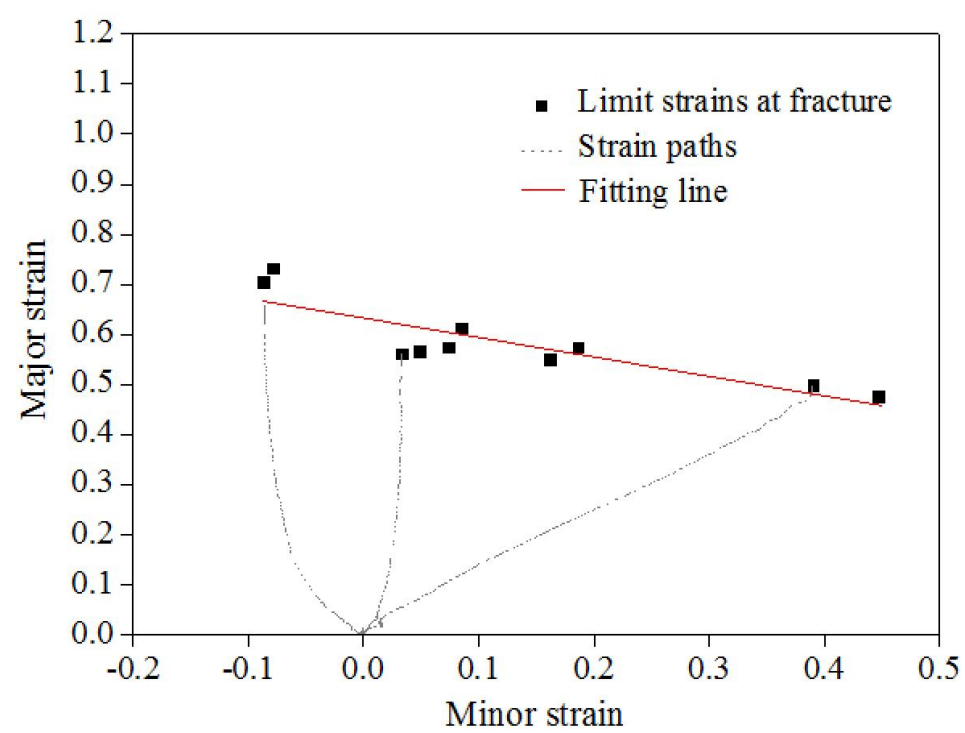

Figure 14: Limit strains at fracture of DP600 under different strain paths 
lines represent the forming limit strains at fracture and the quasi-linear strain paths, respectively.

As show in the above figure, the forming limit strains at fracutre of the DP600 sheet metal are fitted by the Fracture Forming Limit Line (FFL) [9]. The least-square method (Eq. 2) is considered for the fitting process and $\mathrm{k}=-0.39$ and $\mathrm{A}=0.63$ are obtained.

$$
\varepsilon_{\text {major }}=k \varepsilon_{\text {minor }}+A
$$

Figure 15 shows fractures under different strain paths. For all the strain paths, the initial fracture occurs in the centre of the cruciform specimen and all the cracks are perpendicular to the rolling direction.

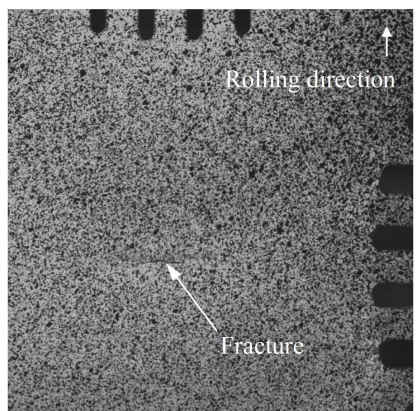

(a) $(-0.09,0.71)$

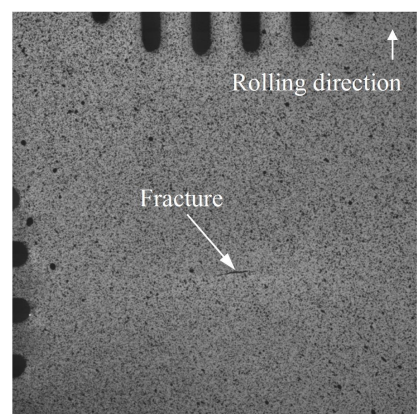

(b) $(0.03,0.56)$

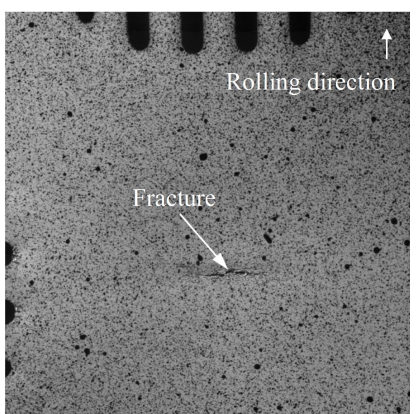

(c) $(0.19,0.58)$

Figure 15: Fracture of cruciform specimens under different strain paths

Figure 16 shows the limit strains at necking and at fracture under different strain paths. The limit strains are higher at fracture than at necking, except for the equibiaxial tension condition. The biggest difference between the FLCF and the FLCN is located near the plane-strain condition. For the equibiaxial tension, three points (A, B and $\mathrm{C}$ ) in the central area are used to identify the onset of necking, as shown in Figure 17. Figure 18 shows the evolution of the equivalent strains of the three points. It can be seen that there is no saturation of equivalent strain until fracture, neither for the point $\mathrm{B}$ or point $\mathrm{C}$. Therefore, no necking occurs under the equibiaxial stretching condition. For this case, the limit strains at fracture determine the deformation achievable. Ductile fracture due to void formation is induced before onset of localized necking. This phenomenon is rather common and 
was frequently observed for aluminium alloys, as reported by Embury et al. for AA5154 [33] or by Takuda et al. [34] for AA5182.

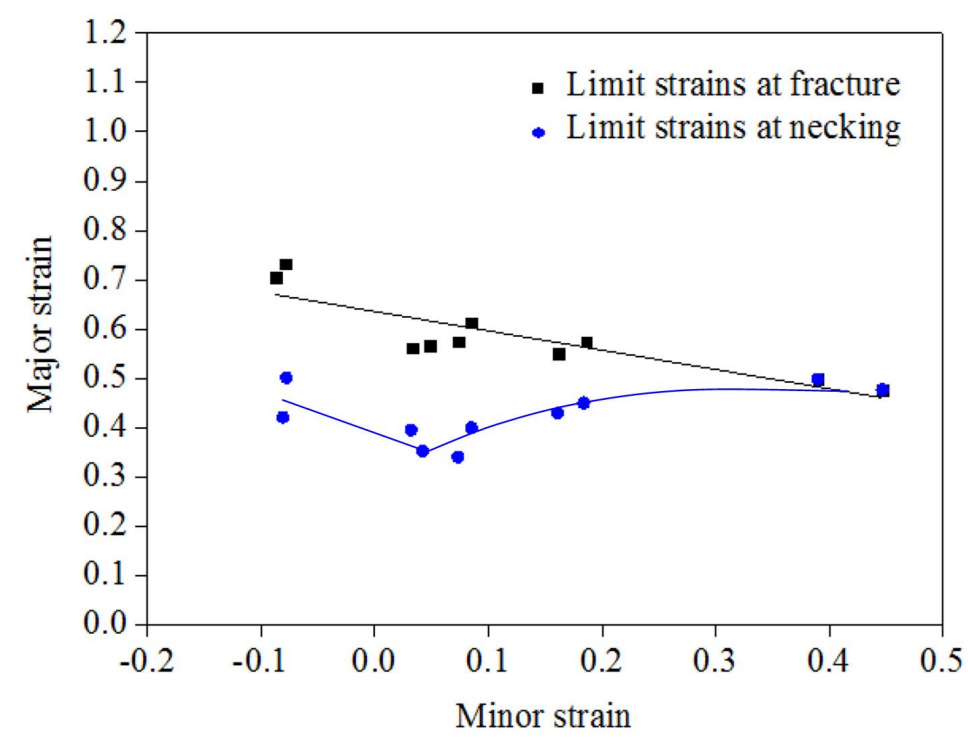

Figure 16: Comparison of limit strains at necking and at fracture under different strain paths

\section{Prediction of the FLCF}

\subsection{Ductile fracture criteria}

Three previously published ductile fracture criteria are selected. Different stress tensor invariants (the hydrostatic pressure $\sigma_{h}$, the maximum principal stress $\sigma_{\max }$ and the equivalent stress $\bar{\sigma}$ ) are considered within these criteria. One or two parameters need to be identified for each criterion. The classical Cockroft and Latham criterion [35] is based on the principal tensile stress, rather than the generalized stress.

$$
\int_{0}^{\bar{\varepsilon}_{f}} \frac{\sigma_{\max }}{\bar{\sigma}} d \bar{\varepsilon}_{p}=C_{1}
$$

Brozzo et al. [36] proposed a modification of Cockroft and Latham criterion to consider the effect of hydrostatic stress explicitly as follows:

$$
\int_{0}^{\bar{\varepsilon}_{f}} \frac{2}{3}\left(1-\frac{\sigma_{h}}{\sigma_{\max }}\right)^{-1} d \bar{\varepsilon}_{p}=C_{2}
$$




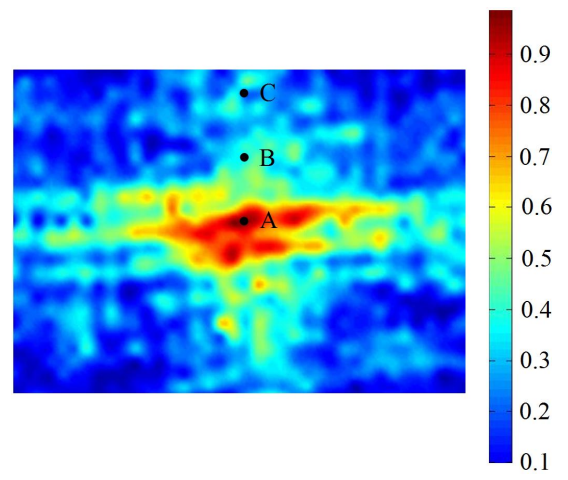

Figure 17: Equivalent strain field of the central area at the time 0.004s before fracture under equibiaxial stretching

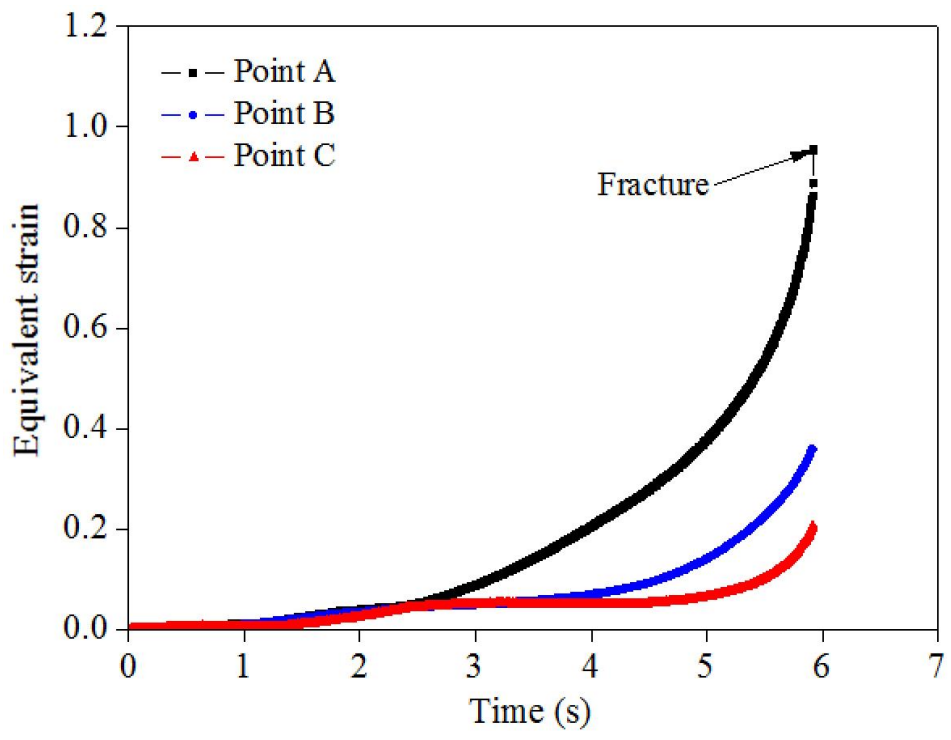

Figure 18: Evolution of equivalent strains under equibiaxial stretching 
The Oyane criterion [37] is derived from the equations of plasticity theory for porous materials as follows:

$$
\int_{0}^{\bar{\varepsilon}_{f}}\left(\frac{\sigma_{h}}{\bar{\sigma}}+C_{3 a}\right) d \bar{\varepsilon}_{p}=C_{3 b}
$$

The fracture will appear when the parameter $C_{i}(\mathrm{i}=1,2,3)$ reaches a critical damage value.

\subsection{Numerical results}

The damage value $C_{i}$ of each criterion can be calculated at every step of the FE simulation of the cruciform specimen by using the user subroutines. Figure 19 shows the predictive results of forming limit strains with the Cockroft and Latham criterion, by introducing different values of $\mathrm{C} 1(0.54,0.57$ and 0.72$)$.

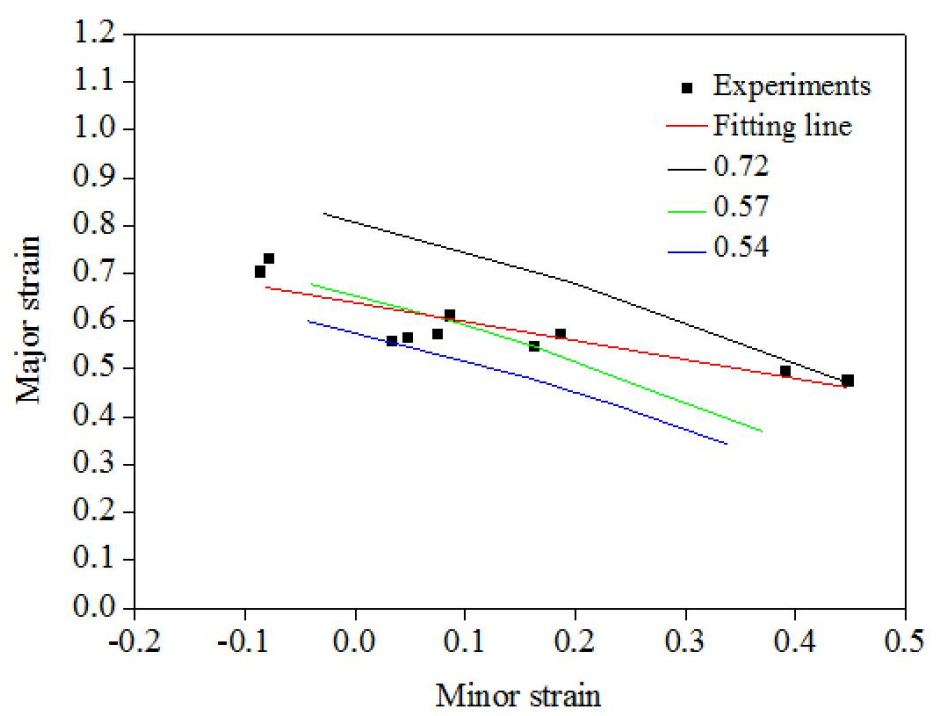

Figure 19: Prediction of forming limits with the Cockroft and Latham criterion, with different values of $\mathrm{C} 1$

For the three values of $\mathrm{C} 1$, the numerical FLCFs from Cockroft and Latham criterion follow a line shape. With the increase of $\mathrm{C} 1$ value, the position of the numerical FLCF changes while the slope keeps almost constant. The solid markers in the Figure 19 correspond to the experimental results identified with the DIC method. These points are fitted by a red line 
with the least-square method. It can be seen that the slopes of the numerical and experimental FLCFs are quite different. For DP600, the Cockroft and Latham criterion is not able to give a reliable prediction of forming limits, whatever the strain path. A calibration of the $\mathrm{C} 1$ value near the plane strain condition will give the best prediction.

The numerical FLCFs calculated by the Brozzo criterion with different values of $\mathrm{C} 2(0.64,0.74$ and 0.84$)$ are shown in Figure 20. The shape of numerical FLCFs is very different from the one from experimental results. Whatever the value of $\mathrm{C} 2$, the limit strains under equibiaxial stretching are significantly underestimated. This criterion is not suitable to predict fracture limits for this material.

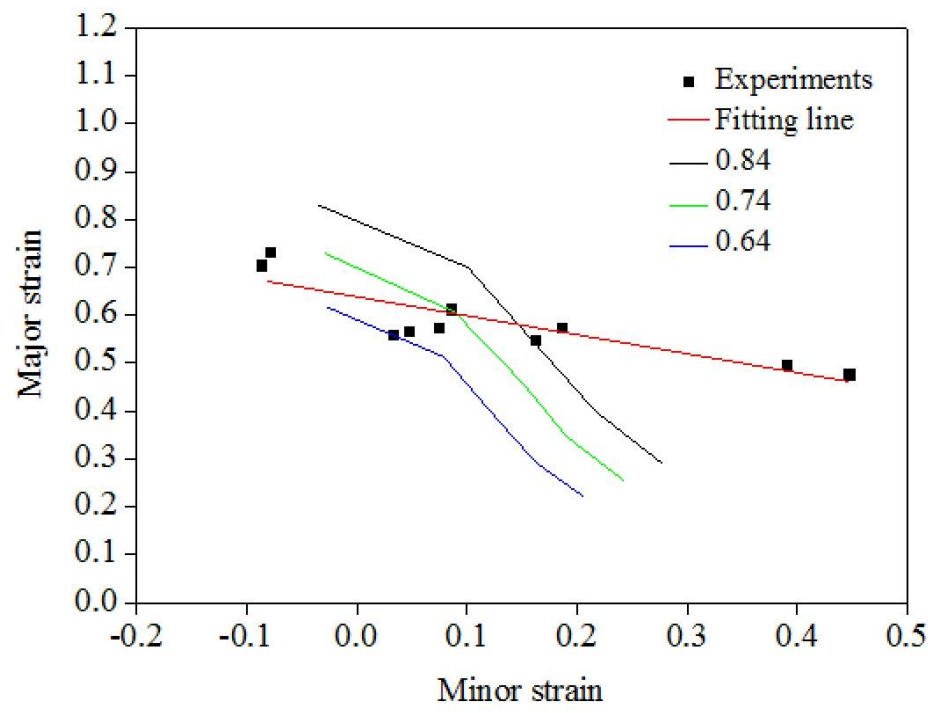

Figure 20: Prediction of forming limits with the Brozzo criterion, with different values of $\mathrm{C} 2$

For the Oyane criterion, two parameters (C3a and C3b) have to be identified (Eq. 5). The slope of the numerical FLCF depends on C3a and the position is controlled by C3b. To get the same slope of experimental FLCF (fitting line), a calibration procedure gives the value of -1 for parameter C3a. Three values of C3b (-0.48, -0.54 and -0.60$)$ are used to discuss the effect of this parameter on the position of the numerical FLCF, as shown in Figure 21. The position is very sensitive to the value of $\mathrm{C} 3 \mathrm{~b}$ and the fitting line of experimental values is used to choose the best value of C3b. The numerical 
FLCF calculated with the value of -0.54 for C3b is almost overlapped by the experimental fitting line. In other words, the Oyane criterion (with the set of values : $\mathrm{C} 3 \mathrm{a}=-1$ and $\mathrm{C} 3 \mathrm{~b}=-0.54)$ predicts well the experimental results, for all the strain paths.

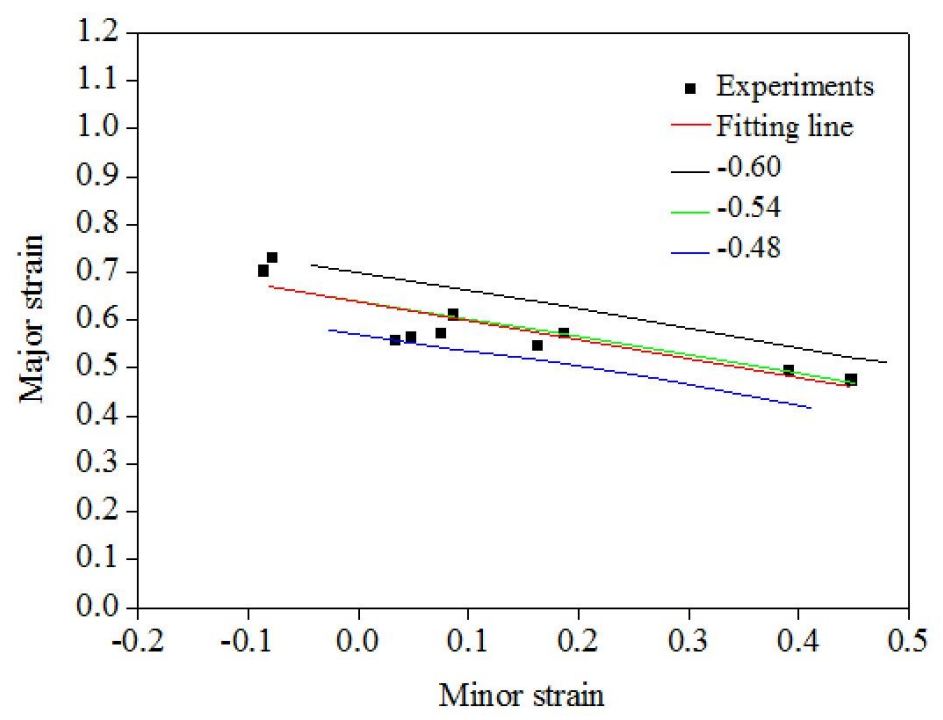

Figure 21: Prediction of forming limits with the Oyane criterion, with different values of $\mathrm{C} 3 \mathrm{~b}$

\section{Conclusions and perspectives}

A summary of designs of cruciform specimen for in-plane biaxial tension test is presented. Based on the numerical results of four redesigned cruciform specimens, an optimized shape is proposed for investigating the forming limits of DP600 sheet metal.

The experimental forming limits at fracture of DP600 sheet metal are determined by the proposed time-dependent method. The forming limit strains are higher at fracture than at necking under different strain paths, except for equibiaxial stretching, for which no necking appears before fracture. The numerical FLCFs with three ductile fracture criteria present various results. The Oyane criterion with two parameters to identify gives the best prediction. 
The effect of the strain path change on the forming limit strains at fracture of the DP600 sheet metal will be discussed in future. The influence of unloading during the strain path change will also be considered. 


\section{References}

[1] W.R. Wang, C.W. He, Z.H. Zhao, and X.C. Wei. The limit drawing ratio and formability prediction of advanced high strength dual-phase steels. Materials \& Design, 32(6):3320-3327, 2011.

[2] F. Ozturk, S. Toros, and S. Kilic. Tensile and spring-back behavior of dp600 advanced high strength steel at warm temperatures. Journal of Iron and Steel Research, International, 16(6):41-46, 2009.

[3] A. Ramazani, M. Abbasi, U. Prahl, and W. Bleck. Failure analysis of dp600 steel during the cross-die test. Computational Materials Science, 64:101-105, 2012.

[4] S. Bruschi, T. Altan, D. Banabic, P.F. Bariani, A. Brosius, J. Cao, A. Ghiotti, M. Khraisheh, M. Merklein, and A.E. Tekkaya. Testing and modelling of material behaviour and formability in sheet metal forming. CIRP Annals-Manufacturing Technology, 63(2):727-749, 2014.

[5] M.B. Silva, P.S. Nielsen, N. Bay, and P.A.F. Martins. Failure mechanisms in single-point incremental forming of metals. The International Journal of Advanced Manufacturing Technology, 56(9-12):893-903, 2011.

[6] H. N. Han and K.H. Kim. A ductile fracture criterion in sheet metal forming process. Journal of Materials Processing Technology, 142(1):231-238, 2003.

[7] X. Song, L. Leotoing, D. Guines, and E. Ragneau. Investigation of the forming limit strains at fracture of aa5086 sheets using an in-plane biaxial tensile test. Engineering Fracture Mechanics, 163:130-140, 2016.

[8] P.A.F. Martins, L. Montanari, V.A. Cristino, and M.B. Silva. Formability and simulative tests in modern sheet metal forming education. In Modern Mechanical Engineering, pages 411-447. Springer, 2014.

[9] K. Isik, M.B. Silva, A.E. Tekkaya, and P.A.F. Martins. Formability limits by fracture in sheet metal forming. Journal of Materials Processing Technology, 214(8):1557-1565, 2014. 
[10] L. Leotoing, D. Guines, I. Zidane, and E. Ragneau. Cruciform shape benefits for experimental and numerical evaluation of sheet metal formability. Journal of Materials Processing Technology, 213(6):856-863, 2013.

[11] L. Leotoing and D. Guines. Investigations of the effect of strain path changes on forming limit curves using an in-plane biaxial tensile test. International Journal of Mechanical Sciences, 99:21-28, 2015.

[12] T. Kuwabara. Advances in experiments on metal sheets and tubes in support of constitutive modeling and forming simulations. International Journal of Plasticity, 23(3):385-419, 2007.

[13] A. Hannon and P. Tiernan. A review of planar biaxial tensile test systems for sheet metal. Journal of materials processing technology, 198(1):1-13, 2008.

[14] P.A. Prates, M.C. Oliveira, and J.V. Fernandes. A new strategy for the simultaneous identification of constitutive laws parameters of metal sheets using a single test. Computational Materials Science, 85:102-120, 2014 .

[15] F. Abu-Farha, L.G. Hector Jr, and M. Khraisheh. Cruciform-shaped specimens for elevated temperature biaxial testing of lightweight materials. JOM, 61(8):48-56, 2009.

[16] T. Kuwabara, S. Ikeda, and K. Kuroda. Measurement and analysis of differential work hardening in cold-rolled steel sheet under biaxial tension. Journal of Materials Processing Technology, 80:517-523, 1998.

[17] T. Kuwabara, A. Van Bael, and E. Iizuka. Measurement and analysis of yield locus and work hardening characteristics of steel sheets wtih different r-values. Acta materialia, 50(14):3717-3729, 2002.

[18] M. Merklein, W. Hußnätter, and M. Geiger. Characterization of yielding behavior of sheet metal under biaxial stress condition at elevated temperatures. CIRP Annals-Manufacturing Technology, 57(1):269-274, 2008. 
[19] D.E. Green, K.W. Neale, S.R. MacEwen, A. Makinde, and R. Perrin. Experimental investigation of the biaxial behaviour of an aluminum sheet. International journal of plasticity, 20(8):1677-1706, 2004.

[20] W. Müller and K. Pöhlandt. New experiments for determining yield loci of sheet metal. Journal of Materials Processing Technology, 60(1):643648, 1996.

[21] D. Banabic, H. Aretz, D.S. Comsa, and L. Paraianu. An improved analytical description of orthotropy in metallic sheets. International Journal of Plasticity, 21(3):493-512, 2005.

[22] F. Abbassi, S. Mistou, and A. Zghal. Failure analysis based on microvoid growth for sheet metal during uniaxial and biaxial tensile tests. Materials \& Design, 49:638-646, 2013.

[23] A. Makris, T. Vandenbergh, C. Ramault, D. Van Hemelrijck, E. Lamkanfi, and W. Van Paepegem. Shape optimisation of a biaxially loaded cruciform specimen. Polymer Testing, 29(2):216-223, 2010.

[24] A. Makinde, L. Thibodeau, and K.W. Neale. Development of an apparatus for biaxial testing using cruciform specimens. Experimental mechanics, 32(2):138-144, 1992.

[25] A. Makinde, L. Thibodeau, K.W. Neale, and D. Lefebvre. Design of a biaxial extensometer for measuring strains in cruciform specimens. Experimental mechanics, 32(2):132-137, 1992.

[26] C.C. Tasan, J.P.M. Hoefnagels, G. Quaak, and M.G.D. Geers. In-plane biaxial loading of sheet metal until fracture. In Proceedings of the 2008 SEM XI international congress and exposition on experimental and applied mechanics, Orlando, Florida, pages 2-5, 2008.

[27] W. Liu, D. Guines, L. Leotoing, and E. Ragneau. Identification of sheet metal hardening for large strains with an in-plane biaxial tensile test and a dedicated cross specimen. International Journal of Mechanical Sciences, 101:387-398, 2015.

[28] R.S. Lee and T. W. Chien. A new method for testing formability in sheet metal forming at biaxial tensile state. In Key Engineering Materials, volume 626, pages 275-280. Trans Tech Publ, 2014. 
[29] I. Zidane, D. Guines, L. Leotoing, and E. Ragneau. Development of an in-plane biaxial test for forming limit curve (flc) characterization of metallic sheets. Measurement Science and Technology, 21(5):055701, 2010 .

[30] W. Liu, D. Guines, L. Leotoing, and E. Ragneau. Identification of strain rate-dependent mechanical behaviour of dp600 under in-plane biaxial loadings. Materials Science and Engineering: A, 676:366-376, 2016.

[31] F. Ozturk, S. Toros, and S. Kilic. Effects of anisotropic yield functions on prediction of forming limit diagrams of dp600 advanced high strength steel. Procedia Engineering, 81:760-765, 2014.

[32] C. Zhang, L. Leotoing, G. Zhao, D. Guines, and E. Ragneau. A comparative study of different necking criteria for numerical and experimental prediction of flcs. Journal of materials engineering and performance, 20(6):1036-1042, 2011.

[33] J. D. Embury and J. L. Duncan. Formability maps. Annual Review of Materials Science, 11:505-521, 1981.

[34] H. Takuda, K. Mori, N. Takakura, and K. Yamaguchi. Finite element analysis of limit strains in biaxial stretching of sheet metals allowing for ductile fracture. International Journal of Mechanical Sciences, 42:785798., 2000.

[35] M.G. Cockroft and D.G. Latham. Ductility and the workability of metals. Journal of the Institute of Metals, 96:33-39, 1968.

[36] P. Brozzo, B. Deluca, and R. Rendina. A new method for the prediction of formability in metal sheets, sheet material forming and formability. In Proceedings of the Seventh Biennial Conference of the IDDRG, 1972.

[37] M. Oyane, T. Sato, K. Okimoto, and S. Shima. Criteria for ductile fracture and their applications. Journal of Mechanical Working Technology, 4(1):65-81, 1980. 